\title{
Development of a novel selection/ counter-selection system for chromosomal gene integrations and deletions in lactic acid bacteria
}

\author{
Winschau F. Van Zyl, Leon M. T. Dicks ${ }^{*}$ and Shelly M. Deane
}

\begin{abstract}
Background: The underlying mechanisms by which probiotic lactic acid bacteria (LAB) enhance the health of the consumer have not been fully elucidated. Verification of probiotic modes of action can be achieved by using singleor multiple-gene knockout analyses of bacterial mutants in in vitro or in vivo models. We developed a novel system based on an inducible toxin counter-selection system, allowing for rapid and efficient isolation of LAB integration or deletion mutants. The Lactococcus lactis nisin A inducible promoter was used for expression of the Escherichia coli mazF toxin gene as counter-selectable marker.
\end{abstract}

Results: The flippase (FLP)/flippase recognition target (FRT) recombination system and an antisense RNA transcript were used to create markerless chromosomal gene integrations/deletions in LAB. Expression of NisR and NisK signalling proteins generated stable DNA integrations and deletions. Large sequences could be inserted or deleted in a series of steps, as demonstrated by insertion of the firefly bioluminescence gene and erythromycin resistance marker into the bacteriocin operons or adhesion genes of Lactobacillus plantarum 423 and Enterococcus mundtii ST4SA.

Conclusions: The system was useful in the construction of L. plantarum 423 and E. mundtii ST4SA bacteriocin and adhesion gene mutants. This provides the unique opportunity to study the role of specific probiotic LAB genes in complex environments using reverse genetics analysis. Although this work focuses on two probiotic LAB strains, $L$. plantarum 423 and E. mundtii ST4SA, the system developed could be adapted to most, if not all, LAB species.

Keywords: Homologous recombination, MazF toxin, Counter-selection, Gene insertion/deletion, Antibiotic marker recycling

\section{Background}

In recent years a profitable probiotic market has emerged, with an increasing number of probiotic-containing supplements conferring specific health benefits to the consumer [1]. Strains of lactic acid bacteria (LAB) and bifidobacteria are the most frequently used as probiotics, and form part of many functional food and dietary supplements [2-4]. Probiotic LAB have a long history of safe use in food and therapeutic products and there is an

\footnotetext{
${ }^{*}$ Correspondence: Imtd@sun.ac.za

Department of Microbiology, Stellenbosch University, Stellenbosch 7600, South Africa
}

increased recognition of their beneficial effects on human health [5]. However, the underlying mechanisms responsible for these effects on the health of the consumer have yet to be fully elucidated and are likely to be multifactorial. If the growing consumer interest in probiotics is to continue, it is crucial to identify the precise mechanisms of action by which probiotics influence human health. One way to provide verification of probiotic modes of action is the use of single or multiple gene knockout analyses of bacterial strains in in vitro or in vivo models [6].

The functional analysis of proteins expressed by genes that confer specific phenotypic properties has underpinned biotechnology for decades. The potential scope of 
such an approach has grown exponentially with the availability of whole-genome sequencing, commercial de novo DNA synthesis and synthetic biology [7]. While many species of LAB are now transformable by electroporation and have thus become amenable to genetic manipulation using plasmid vectors, methods for the isolation of stable and irreversible genetic mutants are still underdeveloped [8-11]. The construction of tailor-made LAB strains for functional genetic analyses is dependent on efficient genetic methods and is often reliant on chromosomal integrations or deletions of specific target genes. This calls for the development of techniques that will allow for the easy and efficient selection of chromosomally- or plasmid-located gene excisions/integrations.

For many years, researchers have used replicative plasmids to express foreign DNA in microorganisms, but these are inherently unstable when expressed in vitro or in vivo where antibiotic selection is not possible, thus limiting their applied utility [12]. To circumvent antibiotic selection-related issues, exogenous DNA must be irreversibly incorporated into a DNA molecule inside the cell. In this way, integration of recombinant DNA is achieved by positioning a selectable marker gene alongside a DNA sequence that is homologous to the target gene of interest within an allele exchange cassette. This has been achieved successfully in yeast and naturally competent Bacillus subtilis that are easily transformable with linear DNA [13]. However, for most bacteria, including LAB, genetic engineering using linear DNA is a challenging task $[14,15]$. Previous studies have demonstrated that genetic recombination in some LAB species using single stranded linear DNA (ssDNA) is possible and that high recombineering efficiencies can be achieved when combined with clustered, regularly interspaced, palindromic repeats (CRISPRs) and a CRISPR-associated (Cas) nuclease [14-16]. However, establishing ssDNA recombination in new species is not trivial and requires extensive optimization procedures to eliminate low recombination frequencies [14]. Consequently, integration plasmids bearing DNA homologous to sites of chromosomal integration may be used to generate desired gene deletions or insertions in the absence of antibiotic marker selection. Desired recombinant cells are specifically selected and isolated using the selectable marker, typically an antibiotic resistance gene. Several sequences can be inserted at multiple loci by simply alternating between selectable markers, usually antibiotic resistance genes, as described in the 'domino' method of Itaya et al. [17]. This method can be effective, but is not without limitations. A major drawback is the availability of suitable antibiotic resistance markers for use as selection/counter-selection markers in the strain of interest. According to this strategy, different antibiotic resistance genes have to be used to introduce multiple chromosomal modifications. Moreover, multi-antibiotic selection pressure could potentially modify the physiology of the recombinant strain or antibiotic genes could potentially be passed to other bacteria.

One method commonly used for the construction of stable integration mutants in $\mathrm{LAB}$ is the use of plasmid vectors containing homologous sequences to the chromosomally located conjugative transposon Tn919, which is utilized as the locus for insertion into the host genome [18, 19]. While this method has been successfully applied in Enterococcus faecalis and Lactococcus lactis, it cannot be used for specific targeted gene deletions. Another method often employed for targeted gene inactivation and DNA chromosomal integrations is based on the use of suicide plasmids [18-25]. In most of these studies, the isolation of successful integrations was straightforward, but strains that have had the plasmid backbone removed may be difficult to isolate. Moreover, single homologous recombination events may be unstable and reversible, resulting in single-crossover mutants with the potential to revert back to the wild-type (WT). This can be overcome by the use of a counter-selection marker located on the plasmid backbone, but the identification of a suitable counter-selection marker under specific conditions to use as a genetic tool can be a challenging task [26, 27]. The upp gene, which codes for uracil phosphoribosyltransferase has been used as a counter-selectable marker in Lc. lactis [28, 29]. The upp gene is responsible for conferring toxicity to cells in the presence of 5-fluorouracil (5-FU), whereas the loss thereof leads to resistance to 5 -FU. The main limitation of using the upp gene as counter-selectable marker is that it is present in the nucleotide metabolic pathway of almost every organism [30]. Another disadvantage is that 5 -FU may be toxic, even in upp mutants, thus further hampering its use as a heterologous counter-selectable marker. Nonetheless, counter-selectable markers have proven invaluable in the construction of clean and unmarked gene deletions or insertions in various unicellular microorganisms [26, 30-36]. For a review on the use of counterselectable markers as genetic tools, refer [26].

This study reports on the development of a strategy generally applicable to all LAB species for the quick and efficient isolation of double-crossover homologously recombined mutants at any genomic loci. We describe the use of a toxin gene as counter-selectable marker placed under the control of the Lc. lactis nisin inducible promoter (PnisA) that forms part of the well-characterized nisin-controlled expression (NICE) system (for a complete review on the NICE expression system, see reference [37]). The PnisA promoter is auto-inducible by nisin in Lc. lactis, but can be induced heterologously in other LAB strains using sub-inhibitory concentrations of nisin $[38,39]$. For heterologous exploitation of the NICE 
system, the nisK and nisR nisin regulatory genes required for signal transduction have to be expressed in conjunction with the use of the PnisA promoter [40]. The E. coli $m a z F$ gene was chosen as a toxin gene for plasmid-borne counter-selection. The mazF gene is an mRNA interferase (sequence-specific endoribonuclease) that forms part of the MazE-MazF toxin-antitoxin (TA) system of $E$. coli, encoded by the mazEF operon [41]. Ectopic expression of the MazF toxin promotes cell death by specifically targeting mRNAs at ACA sequences [42]. In the counter-selection system described here, the expression of the MazF toxin under the control of PnisA is directly coupled to the formation of desired double-crossover mutants using an associated selectable phenotype. Using this method, DNA fragments can be irreversibly inserted or deleted at any genomic locus in L. plantarum 423 and E. mundtii ST4SA in a step-by-step manner. The application of the FLP-FRT recombination system to generate markerless homologously recombined mutants is also demonstrated. This method is applicable to many, if not all, transformable LAB species.

\section{Results}

\section{Construction and optimization of the nisin-inducible counter-selection marker system}

The heterologous use of PnisA originating from the $L c$. lactis nisin A lantibiotic producer strain was optimized for the probiotics L. plantarum 423 and $E$. mundtii ST4SA. The plasmid pNZmazFnisRK (Fig. 1) containing the mazF toxin gene under control of the Lc. lactis nisininducible promoter, together with the regulatory genes, nisR and nisK, was introduced into the probiotic LAB strains, giving rise to $E$. mundtii ST4SA pNZmazFnisRK and L. plantarum 423 pNZmazFnisRK. Their MazF response to induction with varying concentrations of nisin was then evaluated (Fig. 2 and Additional file 1: Fig. S1). Previous studies $[37,38]$ reported that low sub-inhibitory concentrations of nisin, ranging from 0.1 to $5.0 \mathrm{ng} /$ $\mathrm{ml}$, were sufficient for PnisA-controlled gene expression in Lc. lactis pNZ9000. We found that the PnisA promoter responded to much higher sub-inhibitory concentrations of nisin, ranging from 300 to $400 \mathrm{ng} / \mathrm{ml}$ in E. mundtii ST4SA pNZmazFnisRK (Fig. 2a) and 300 to $600 \mathrm{ng} / \mathrm{ml}$ nisin in L. plantarum 423 pNZmazFnisRK after $7 \mathrm{~h}$ of induction (see Additional file 1: Fig. S1). Control strains transformed with pNZ8048 and recombinant strains transformed with pNZmazFnisRK without nisin induction showed no significant differences in growth after $7 \mathrm{~h}$. This suggested that no significant promoter leakiness was occurring that could potentially result in premature cell growth arrest without nisin induction of PnisA. No significant difference in growth rate was recorded for control strain E. mundtii ST4SA pNZ8048 with $(300 \mathrm{ng} / \mathrm{ml})$

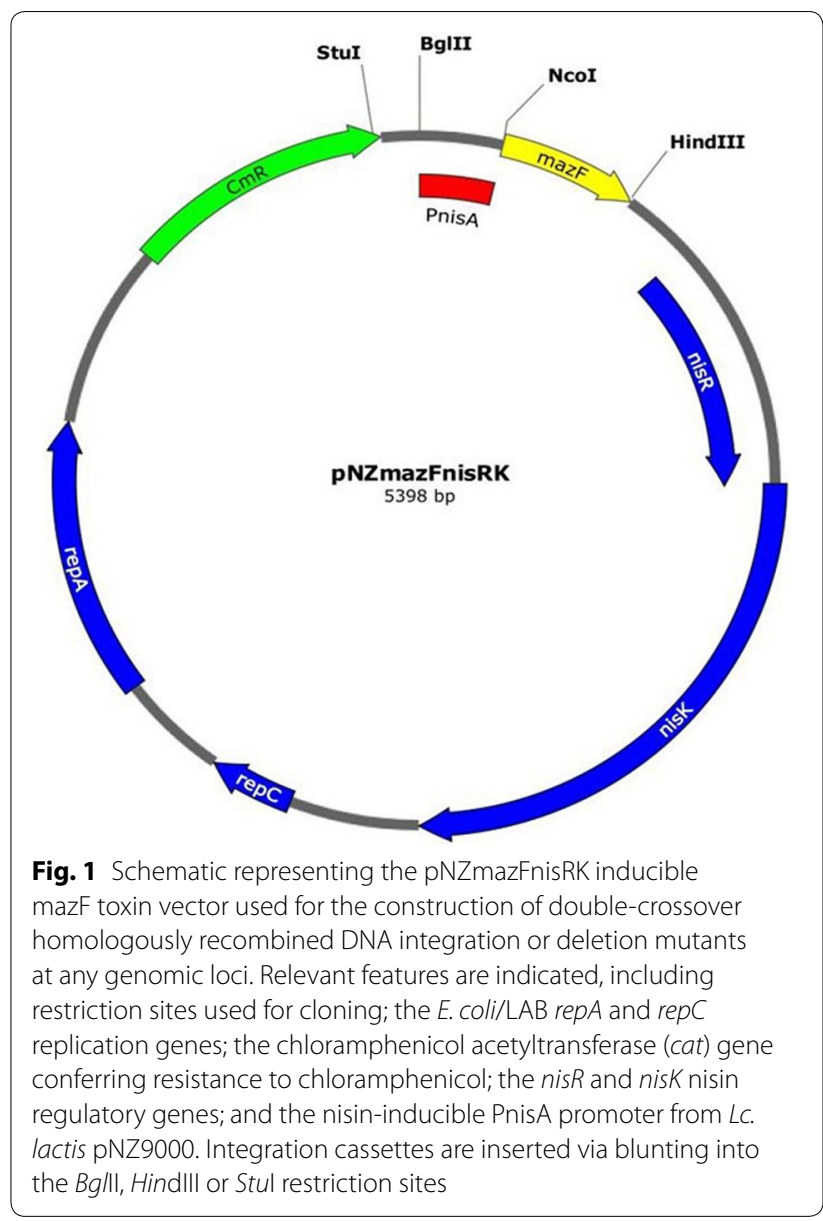

or without nisin induction, whereas a significant growth difference was recorded for recombinant $E$. mundtii ST4SA pNZmazFnisRK when induced with nisin at the same concentration (Fig. 2a). No significant growth inhibition was observed for control strain L. plantarum 423 pNZ8048 when induced with nisin concentrations ranging from 100 to $600 \mathrm{ng} / \mathrm{ml}$ compared to un-induced. A significant inhibition of growth was recorded when strain L. plantarum 423 pNZmazFnisRK was induced with nisin at $600 \mathrm{ng} / \mathrm{ml}$ as compared to when no nisin was present (see Additional file 1: Fig. S1). For all further nisin induction experiments, a nisin induction concentration of $300 \mathrm{ng} / \mathrm{ml}$ was used for PnisA-carrying $E$. mundtii ST4SA and $600 \mathrm{ng} / \mathrm{ml}$ for L. plantarum 423. Taken together, these results confirmed that the MazF protein toxicity would enable its application in LAB as an efficient counter-selection marker for the isolation of double-crossover mutants.

Lactococcus lactis pNZ9000 transformed with plasmid pNZmazF, and recombinant strains L. plantarum 423 pNZmazFnisRK and E. mundtii ST4SA pNZmazFnisRK were plated onto M17 or MRS agar 


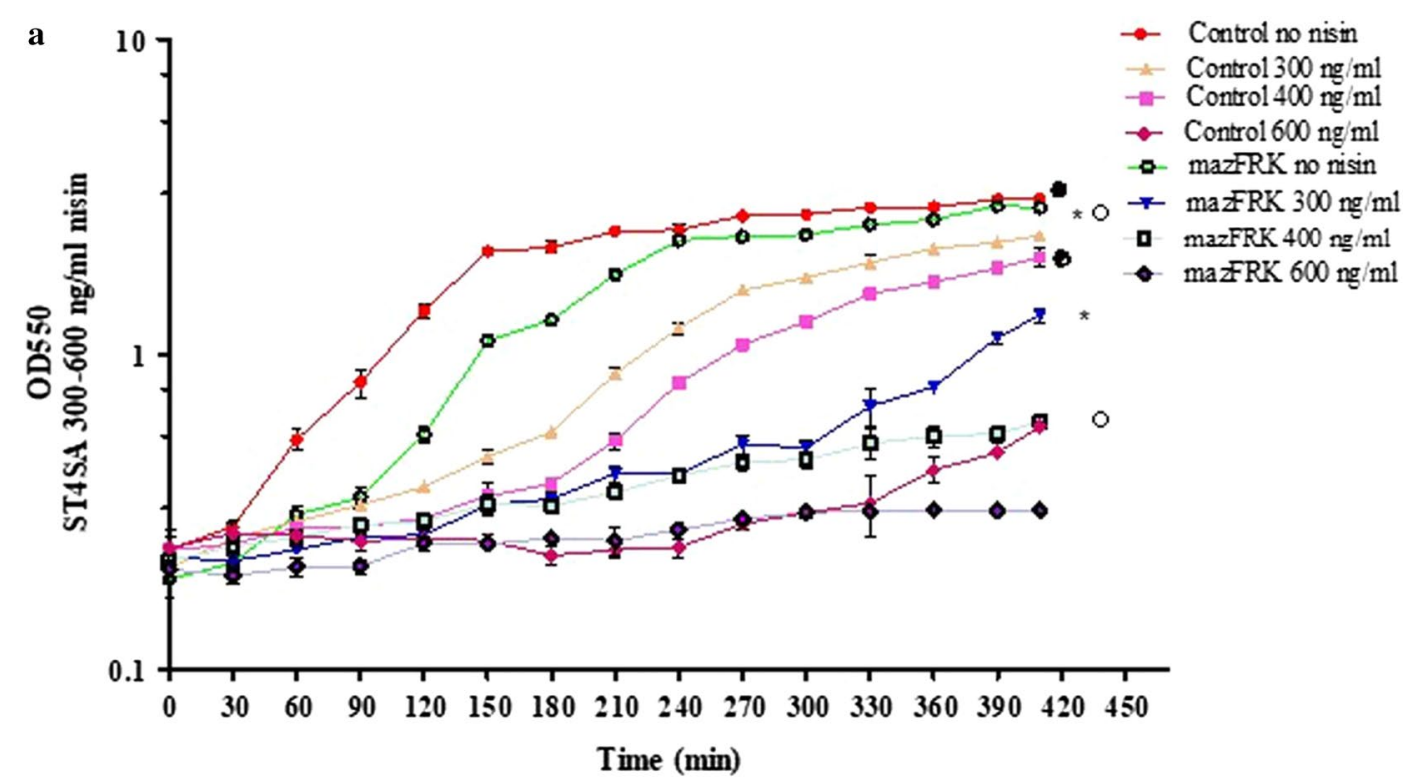

b

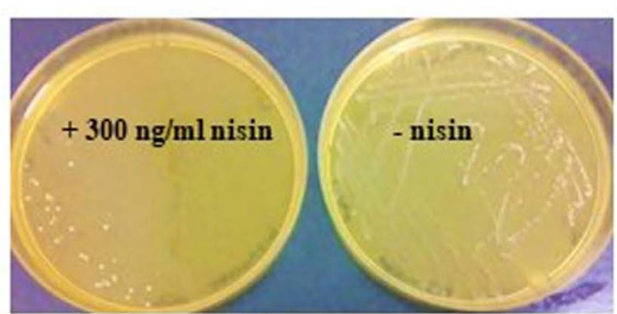

Fig. 2 Optimization of nisin-controlled mazF gene expression in E. mundtii ST4SA. a Growth comparison of E. mundtii ST4SA transformed with the empty pNZ8048 vector (control) and E. mundtii ST4SA transformed with the PnisA-controlled mazF gene pNZmazFnisRK plasmid in sub-inhibitory concentrations of nisin (0-600 ng/ml). Significant differences were assessed using the Kruskal-Wallis nonparametric test, and are indicated with a filled circle $(P<0.05)$ for comparison between Control no nisin and control $400 \mathrm{ng} / \mathrm{ml}$, an asterisk $(P<0.05)$ for comparison between mazFRK no nisin and mazFRK $300 \mathrm{ng} / \mathrm{ml}$ and an empty circle $(P<0.05)$ for comparison between mazFRK no nisin and mazFRK $400 \mathrm{ng} / \mathrm{ml}$. b MRS agar plates representative of the effect of MazF protein expression in E. mundtii ST4SA harboring the pNZmazFnisRK plasmid in the absence of nisin (-nisin) and in the presence of nisin $(+300 \mathrm{ng} / \mathrm{ml}$ nisin)

plates supplemented with chloramphenicol $(\mathrm{Cm})$ in the absence and presence of nisin. After $24 \mathrm{~h}$ of incubation at $30{ }^{\circ} \mathrm{C}$, plates containing nisin showed very little or no growth, while those without nisin showed an abundance of growth (Fig. 2b, Additional file 1: Fig S2). To further demonstrate the application of the nisin-induction system in LAB, Lc. lactis pNZ9000 was transformed with plasmid pNZCherry, while $L$. plantarum 423 and E. mundtii ST4SA were transformed with plasmid pNZCherrynisRK. In both vectors, the $m$ Cherry red fluorescence gene was placed downstream of the PnisA promoter (Additional file 1: Table S1). The PnisA nisin-induced expression of mCherry fluorescence protein was easily detected on agar plates containing nisin by the appearance of pink colonies, while those lacking nisin remained white or cream (see Additional file 1: Fig. S2).
Integration of large DNA fragments and deletion of the $L$. plantarum 423 and E. mundtii ST4SA bacteriocin genes

To demonstrate the feasibility and efficiency of the nisinMazF counter-selection marker system in LAB, the E. mundtii ST4SA munA mundticin bacteriocin gene located on a megaplasmid [43] and the plaA plantaricin bacteriocin gene located on the L. plantarum 423 pPLA4 plasmid [44] were targeted for inactivation. The munA knock-out (KO) plasmid carried a 2471 bp cat-ffluc gene cassette (see Additional file 1: Fig. S3), while the plaA KO plasmid carried a 3204 bp erm-ffluc gene cassette (see Additional file 1: Fig. S4), flanked by regions of homology required for homologous recombination. The pNZKOmunA::CatFfluc included a 135 bp internal fragment of the munA ORF in the upstream region of homology, resulting in the deletion of $18 \mathrm{bp}$ of the $153 \mathrm{bp}$ munA 


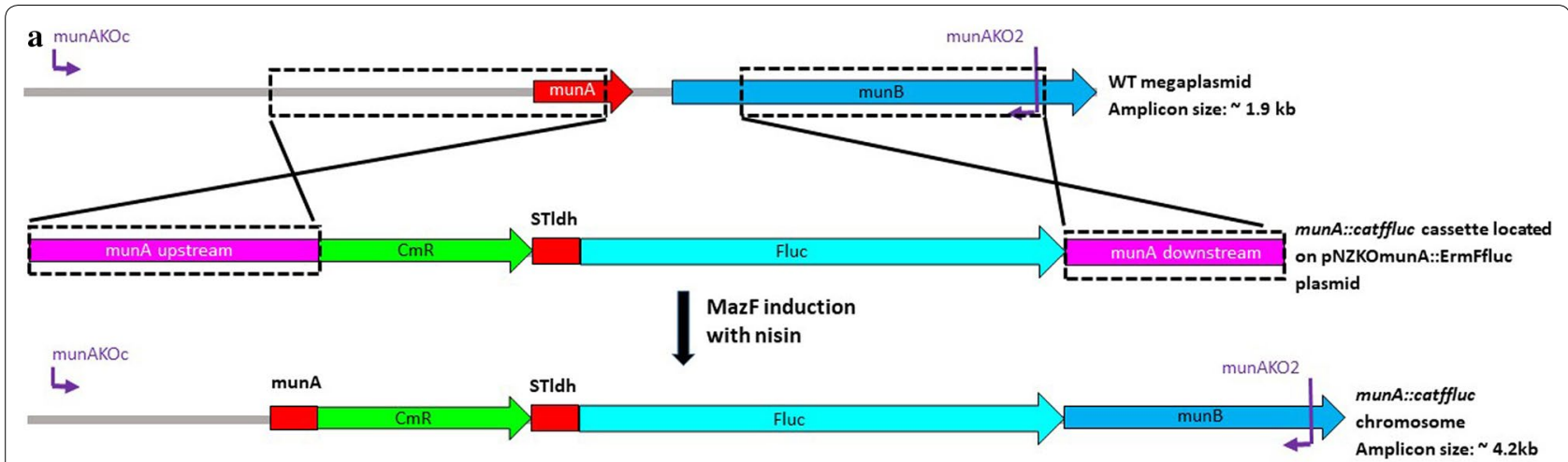

b

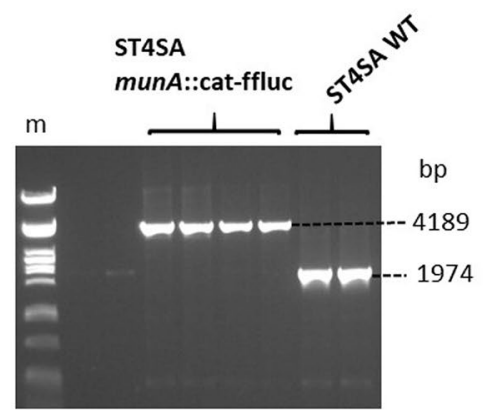

Fig. 3 Gene deletion and integration via homologous recombination into the genome of E. mundtii ST4SA at the munA bacteriocin gene locus to create E. mundtii ST4SA munA::cat-ffluc. a Homologous recombination between the wild-type (WT) E. mundtii ST4SA munA-carrying megaplasmid and the munA:.:catffluc cassette. Boxed regions show the upstream $(\sim 0.9 \mathrm{~kb})$ and downstream regions $(\sim 0.6)$ of homology on the megaplasmid and the pNZKOmunACatFfluc knockout $(\mathrm{KO})$ vector. Cells harboring the munA KO vector were selected on $\mathrm{Cm}$ and Em, followed by nisin induction for MazF toxin expression to select for mutants that have lost the plasmid backbone bearing erm and mazF genes. Double crossover mutants were selected and screened by PCR using the indicated primer combinations. b PCR amplification of WT and munA deletion and insertion mutants using the primer pair indicated in panel (a). Primer pairs are shown in purple. (m) Lambda DNA digested with Pstl (NEB). Amplicons from four munA mutant and two WT colonies, respectively, are shown

gene in all E. mundtii ST4SA munA::cat-ffluc mutants (Fig. 3a). Refer to Table 2 for a detailed description of the components of all regions of homology for targeted gene inactivation. Similarly, pNZKOplaA::ErmFfluc plasmid included a $69 \mathrm{bp}$ internal fragment of the plaA ORF in the downstream region of homology, resulting in the deletion of $102 \mathrm{bp}$ of the $171 \mathrm{bp}$ plaA gene in all L. plantarum 423 plaA::erm-ffluc mutants (see Additional file 1: Fig. S5). Double crossover mutants were isolated by following the protocol described in "Materials and methods" (also refer to Additional file 1: Fig. S6). Enterococcus mundtii ST4SA munA::cat-ffluc double- crossover mutants retained resistance to $\mathrm{Cm}$, but not Em (erythromycin), in turn indicating the loss of the plasmid backbone DNA encoding the mazF and erm genes. No double-crossover mutants were obtained in the absence of antibiotic selection. Lactobacillus plantarum 423 plaA::erm-ffluc mutants retained resistance to $\mathrm{Em}$, but not to $\mathrm{Cm}$, indicating that the erm-ffluc gene cassette was successfully integrated onto the pPLA4 plasmid without the plasmid backbone DNA encoding the $m a z F$ and cat genes. Knockout mutants that appeared on nisin plates were screened by PCR and DNA sequencing using primer combinations listed in Additional file 1: Table S2. Enterococcus mundtii ST4SA munA::cat-ffluc mutants contained the $2471 \mathrm{bp}$ cat-ffluc "cargo" DNA via allelic exchange, with the consequent deletion of a $260 \mathrm{bp}$ DNA fragment from the munA operon harbored on a megaplasmid as confirmed by PCR as well as sequencing (Fig. 3b). Similarly, L. plantarum 423 plaA::ermffluc mutants retained the erm-ffluc cassette via allelic exchange and the deletion of a $208 \mathrm{bp}$ fragment from the plaA operon on the pPLA4 native plasmid as confirmed by PCR as well as sequencing (see Additional file 1: Fig. S5).

Supernatants isolated from L. plantarum 423 plaA::erm-ffluc and E. mundtii ST4SA munA::cat-ffluc mutants did not result in the formation of clear inhibition zones on plates overlaid with the sensitive $L$. monocytogenes EGDe strain as compared to the WT derivatives of each strain (see Additional file 1: Fig. S7). Similarly, supernatants isolated from sonicated 
$p l a A^{-}$and $m u n A^{-}$mutant cell cultures did not result in the formation of inhibition zones on agar plates overlaid with L. monocytogenes EGDe (not shown). These results confirmed that the bacteriocin genes of the probiotic strains were successfully inactivated using the nisin-MazF counter-selection method. To test the active expression of the integrated fluc bioluminescence gene, L. plantarum 423 plaA::erm-ffluc and E. mundtii ST4SA munA::cat-ffluc mutants were imaged using the Caliper in vivo imaging system (IVIS; Caliper Life Sciences, Hopkinton, MA, USA). A strong bioluminescent signal was detected from colonies formed on agar plates for each of the mutant strains (see Additional file 1: Fig. S8).

\section{Integration and removal of the FRT-flanked erm gene in $L$. plantarum 423 for marker recycling}

To overcome the limited availability of antibiotic resistance markers that are suitable for use in LAB as integrative selective markers, the $S$. cerevisiae FLP-FRT recombination system was adapted for marker recycling. A gene disruption mutant of the L. plantarum 423 aap adhesion-associated gene was generated by utilizing the erm gene flanked by two direct repeat FRT recombination targets for excision by FLP recombinase. The generated sizes of the WT L. plantarum 423 and integrant loci are shown in Fig. 4a. Lactobacillus plantarum 423 aap::frt-erm mutants were successfully isolated via nisin induction of the mazF toxin gene. Double-crossover mutants selected on nisin-supplemented MRS agar plates retained resistance to $\mathrm{Em}$, but not $\mathrm{Cm}$, confirming the loss of the cat and mazF gene coding plasmid backbone. The recombination event, namely, the insertion of the FRT-erm gene onto the aap ORF locus, was confirmed by PCR and the resulting amplicon sizes are shown in Fig. 4b. PCR amplification of aap mutant gDNA resulted in a 3696 bp fragment compared to the $2238 \mathrm{bp}$ fragment in the WT derivative.

Lactobacillus plantarum 423 aap::frt-erm mutants transformed with the pNZFLPasRNA_repA plasmid, were resistant to $\mathrm{Em}$ and $\mathrm{Cm}$ (resulting from the cat gene on the newly-introduced plasmid). The induction of FLP recombinase resulted in the isolation of unmarked aap mutant $L$. plantarum aap::frt_um (um-unmarked) colonies that have lost the erm gene via FRT-FLP excision as confirmed by PCR and sequencing (Fig. 4a, b).

Once excision of the erm antibiotic resistance marker in L. plantarum aap::frt_um colonies was confirmed, loss of the FLP recombinase plasmid was stimulated by the expression of a 350 bp asRNA repA transcript by induction with nisin. Lactobacillus plantarum aap::frt_um mutants did not show any colony growth on MRS agar plates supplemented with nisin and $\mathrm{Cm}$, indicating plasmid loss, while colonies that were not induced by nisin showed an abundance of growth (indicating the presence of the plasmid, Fig. 4c).

\section{Isolation of srt $A$ and $s r t C$ deletion mutants using regions of homology containing small ( $<60 \mathrm{bp}$ ) $5^{\prime}$ and $3^{\prime}$ end sequences}

Although the PnisA-MazF counter-selection system proved to be functional, the E. mundtii ST4SA $s r t A$ and srtC genes did not contain sufficient restriction enzyme sites to allow cloning of integrative gene cassettes flanked by homologous arms. A strategy to introduce new restriction sites would facilitate the cloning of integrative genes in between homologous regions to enable the inactivation of target sequences with insufficient restriction enzyme digestion sites. To do this, srtA and $s r t C \mathrm{KO}$ plasmids carrying upstream and downstream regions of homology with new restriction sites for integrative gene cassette insertion were constructed (see Additional file 1: Figs. S9 and S10). Both KO plasmids were designed to facilitate the deletion of the majority of the $\operatorname{srt} A$ and $s r t C$ genes sequences (with $<60$ bp of the $5^{\prime}$ and $3^{\prime}$ ends of the gene coding sequences included in the upstream and downstream regions of homology). The FRT-flanked erm gene was utilized as integrative cassette and the anticipated sizes of the WT E. mundtii ST4SA and integrant srtA loci are shown in Fig. 5a. Enterococcus mundtii ST4SA WT and integrant srtC loci are shown in Additional file 1: Fig. S11. The deletion mutant isolation protocol was followed to enrich for recombinant cells that have undergone the desired double-crossover recombination event. Enterococcus mundtii ST4SA srtA::frt-erm mutants were successfully isolated that resulted in the deletion of a $580 \mathrm{bp}$ fragment of the $714 \mathrm{bp} s r t A$ ORF as confirmed by PCR and sequencing (Fig. 5b). Similarly, the expected band sizes of E. mundtii ST4SA srtC::frt-erm mutants were obtained as confirmed by PCR, sequencing and restriction digests, that resulted in the deletion of a $726 \mathrm{bp}$ internal fragment of the $826 \mathrm{bp} s r t C$ ORF (see Additional file 1: Fig. S11).

To verify the loss of the $E$. mundtii ST4SA srtA aggregation substance's (AS) ability in srtA KO mutants to attach secreted adhesion proteins to the bacterial cell surface, a cell clumping assay was performed. In WT E. mundtii ST4SA cells, AS expression lead to a marked clumping of bacterial cells to form large cell aggregates that settled at the bottom of the tube (Fig. 5c). In the $s r t A \mathrm{KO}$ strain lacking AS, the cell suspension remained turbid, thus indicating the loss of the cells' ability to form aggregates compared to the WT (Fig. 5d). In the tube containing E. mundtii ST4SA sortaseC KO cells, the bacteria maintained the ability to form aggregates that settled at the bottom of the tube (Fig. 5e). These results confirmed the 


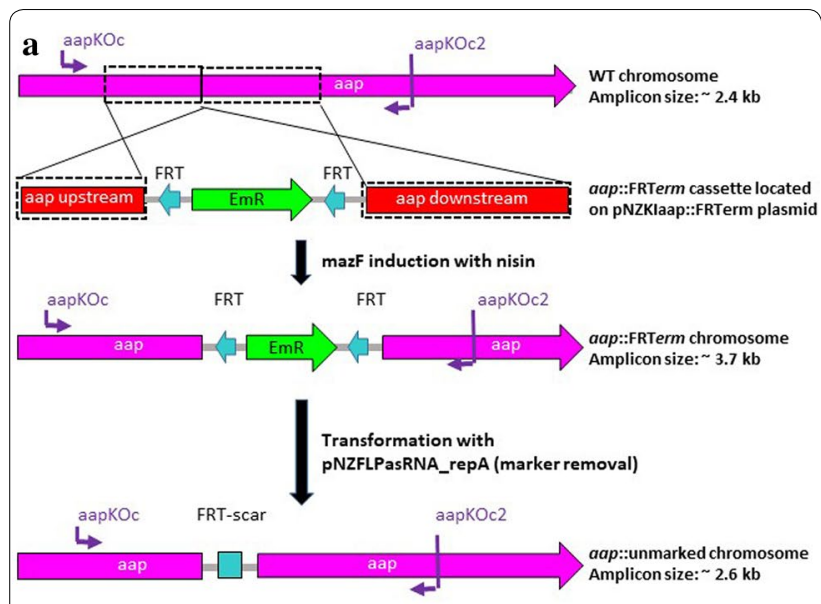

b

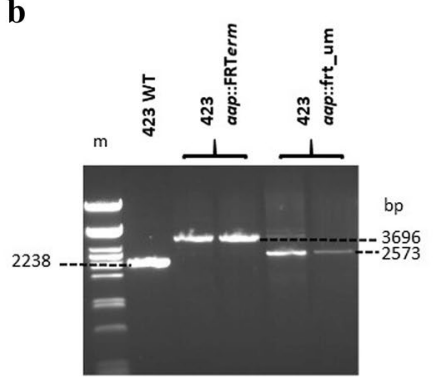

c

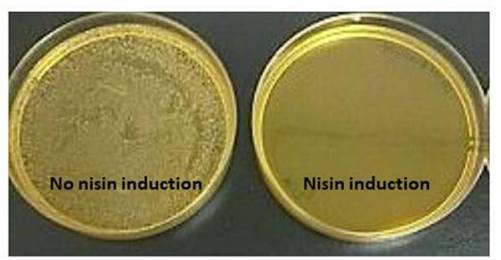

Fig. 4 Gene inactivation and integration via homologous recombination into the genome of L. plantarum 423 at the aap adhesion gene locus to create L. plantarum 423 aap::FRTerm and L. plantarum 423 aap::frt_um (um-unmarked). a Homologous recombination between the wild-type (WT) L. plantarum 423 chromosome and the aap::FRTerm cassette and selection of unmarked aap double-crossover mutants. Boxed regions show the upstream and downstream regions of homology ( $0.9 \mathrm{~kb})$ on the WT L. plantarum 423 chromosome and plasmid pNZKlaap::FRTerm knock-in (KI) vector. Cells harboring the aap KI vector were selected on $\mathrm{Cm}$ and $\mathrm{Em}$, followed by nisin induction for MazF toxin expression to select for mutants that have lost the plasmid backbone bearing cat and mazF genes. Double crossover mutants were selected and screened by PCR using the primer combinations indicated in purple. b PCR amplification of WT L. plantarum 423 and aap insertion mutants using the primer pair indicated in panel A. Additionally, the Em resistance marker was recycled via excision by FLP recombinase. (m) Lambda DNA digested with Pstl (NEB). Amplicons from one WT, two aap::FRTerm insertion mutant and two aap::unmarked colonies are shown. c MRS agar plates showing the effectiveness of the repA asRNA induction of FLP recombinase-bearing plasmid loss in the absence of nisin (no nisin induction) and in the presence of nisin (nisin induction). Colonies that have lost the repA-bearing plasmid were isolated via replica plating
SortaseA mutant phenotype and that the SortaseA AS is required for the aggregation of cells.

\section{Discussion}

The functional genetic analysis of genes that confer specific phenotypical properties in LAB is highly dependent on the application of an effective counter-selection marker system for the easy and efficient isolation of chromosomally- or plasmid-located allelic exchange mutants $[11,26,27]$. While the use of replicative plasmids to study protein functions is easy to implement, multi-copy plasmids are not suited for in vitro or in vivo models where antibiotic selection for plasmid maintenance is not possible [12]. The integration or deletion of genes at any specified locus circumvents antibiotic selection related issues. Most of the techniques currently used for the isolation of homologous recombination mutants in LAB are subject to the following limitations: a lack of broad applicability amongst different LAB species, an inability to target specific gene loci, a shortage of suitable antibiotic resistance markers, and failure to isolate irreversible double-crossover mutants [17-19, 28, 29, 45, 46].

Counter-selection markers are invaluable for the construction of stable double-crossover mutants, especially in probiotic $\mathrm{LAB}$, where the mechanisms by which they exert their beneficial effects on the consumer can be studied by reverse genetic analysis $[26,46]$. Nevertheless, the identification and optimization of suitable counterselection markers is a challenging and laborious task.

In this study, a method was developed to easily and efficiently isolate stable irreversible double-crossover mutants in L. plantarum 423 and E. mundtii ST4SA. The E. coli mazF toxin gene was placed under the control of the PnisA nisin-inducible promoter that is strictly associated with the nisR and nisK nisin signal regulatory genes, to form the pNZmazFnisRK destination plasmid [37]. A major advantage of the NICE system over other inducible gene expression systems, is the tightly controlled gene expression that has been used to produce large amounts of enzymes for food, medical or technical applications $[47,48]$. This study has shown that MazF expression is tightly controlled by the nisin-inducible promoter. This eliminates any potential MazF-induced premature cell growth arrest as a result of promoter leakiness.

Growth conditions were successfully optimized for the mazF counter-selection gene to promote the death of cells harbouring mazF upon induction of the PnisA promoter with nisin. This approach ensures that transformants that have undergone only a single event of homologous recombination (thus retaining a copy of the plasmid-located counter-selection marker in the chromosome), are eliminated in the presence of nisin-induced MazF toxin. This method was used to construct deletions 


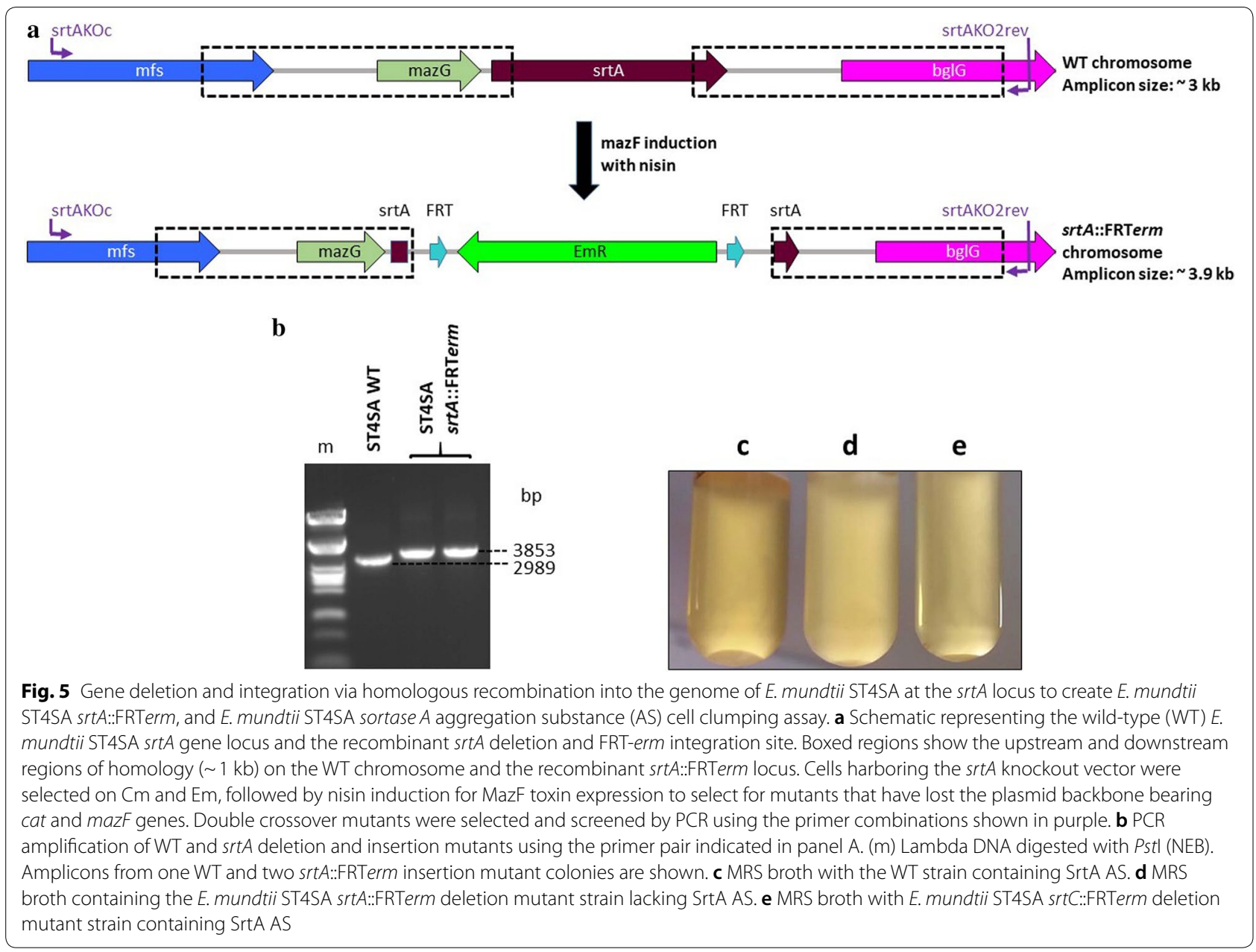

within the ORFs of specific genes, to introduce a gene of interest, to construct an unmarked mutation and to realize gene deletion mutants using small regions of homology. In the first case, bacteriocin gene deletion mutants of L. plantarum 423 and E. mundtii ST4SA were constructed, while simultaneously inserting the large $1.6 \mathrm{~kb}$ ffluc firefly luciferase reporter gene. The $L$. plantarum 423 plaA bacteriocin $\mathrm{KO}$ plasmid was designed to delete the majority of the plaA ORF while ensuring that none of the adjacent genes would be affected. In a previous study [49], the L. plantarum $423 \mathrm{WT}$ strain was cured of the pPLA4 plaA gene-encoding plasmid to produce a bacteriocin-deficient mutant. While their approach proved successful, the loss of the whole plasmid may be undesirable because of the consequent loss of all bacteriocin-adjacent genes. The E. mundtii ST4SA munA bacteriocin $\mathrm{KO}$ plasmid was designed for the deletion of $18 \mathrm{bp}$ of the munA ORF. The bacteriocin gene deletions of both L. plantarum 423 and E. mundtii ST4SA resulted in the loss of bacteriocin production, confirmed against
L. monocytogenes EGDe. Supernatants isolated from the bacteriocin-deficient mutant strains lacked the ability to form clear inhibition zones as compared to the wild type derivatives. Bioluminescence imaging revealed that the integrated ffluc gene was actively expressed in each of the bacteriocin $\mathrm{KO}$ mutants. Strong bioluminescence emission was detected from colonies on MRS agar plates, indicating the functional expression of the Ffluc protein at the integrated loci. These results demonstrate the feasibility and applied utility of the newly developed counter-selectable marker system.

Desired double-crossover mutants are usually isolated using an antibiotic resistance gene as integrative selective marker [17]. However, repeated manipulations of any bacterial chromosome can only be achieved by the generation of markerless integration mutants due to a limited availability of suitable antibiotic resistance markers. An easy-to-implement marker recycling system for $\mathrm{LAB}$ allows microbiologists to genetically engineer $\mathrm{LAB}$ strains for biotechnological production processes. In 
this study, the $S$. cerevisiae FLP-FRT recombination system was modified for application in LAB. The FLP-FRT recombination system is present in most yeast strains and is encoded by the $2 \mu \mathrm{m}(6.4 \mathrm{~kb})$ plasmid [50, 51]. Two flanking 34 bp FLP recognition targets (FRT) are necessary for successful excision of an integrated fragment by FLP recombinase. The yeast FLP-FRT system has been successfully applied in several pathogenic and non-pathogenic Gram-negative and Gram-positive bacteria [36, 52-54]. The L. plantarum 423 aap mucus adhesion gene was targeted for inactivation with the insertion of an FRT-flanked erm resistance gene [55]. Once FRTerm gene insertion was confirmed, a two-step process was followed for marker recycling. In the first step, FLP recombinase activity was induced by transformation with plasmid pNZFLPasRNA_repA to produce unmarked aap KO mutants. Secondly, once excision of the erm gene was confirmed, loss of the pNZFLPasRNA_repA plasmid was stimulated by a 350 bp repA antisense RNA (asRNA) transcript placed under the control of the PnisA nisininducible promoter. The repA asRNA is a single-stranded RNA molecule that is complementary to the repA mRNA molecule of pNZ8048-derived vectors. The repA asRNA inhibits translation of the $\operatorname{rep} A$ origin of replication (ori) by binding to the first $350 \mathrm{bp}$ of the complementary rep $A$ mRNA transcript [56]. As a result, the strain was cured of the repA ori-containing plasmid via repA protein synthesis inhibition. Previous studies have used asRNA successfully to modulate the expression of specific genes or to prevent the proliferation of bacteriophages in Grampositive bacteria, including many LAB sp. [57-63]. The system developed in this study requires minimal effort (days) for the isolation of unmarked mutants based on the strength and specificity of the NICE system. The resulting aap $\mathrm{KO}$ unmarked strain, free of antibiotic selection markers, may be used for further genetic manipulations of the L. plantarum 423 chromosome in a similar manner.

To further demonstrate the strength of the newly developed system, gene deletion mutants of the $E$. mundtii ST4SA srtA and srtC genes were generated using homologous arms containing $<60$ bp regions $\left(5^{\prime}\right.$ and $\left.3^{\prime}\right)$ homologous to the target genes. This approach ensured that none of the adjacent genes were affected while deleting the majority of each target. Emphasis is placed on the introduction of new restriction sites in homologous arm regions for the insertion of integration cassettes to ensure optimal cloning of integrative cassettes. This strategy ensures the inactivation of gene targets that may not contain sufficient restriction sites to facilitate the cloning of integrative genes, usually antibiotic resistance genes, flanked by homologous regions. The technique used in this study ensures the isolation of recombination mutants even when using small regions $(<60 \mathrm{bp})$ of the coding sequence of a target, included in larger homologous arms containing sequences adjacent to the target genes.

\section{Conclusions}

The method described in this paper is easy to implement, highly efficient and can be used to manipulate the chromosomes of Lactobacillus and Enterococcus spp. Furthermore, the strategy is well adapted for use in other LAB sp. due to the broad applicability of the nisin expression system. This provides a unique opportunity to study the role of specific probiotic LAB genes in complex environments using reverse genetics analysis. In addition to the efficient deletion or integration of genes at any defined loci, the use of the FLP/FRT recombination system provides marker recycling for further manipulations of LAB strains.

\section{Materials and methods \\ Bacterial strains, plasmids and culture media}

Bacterial strains and general cloning plasmids are listed in Table 1 and Additional file 1: Table S1. All subcloning experiments were done in E. coli DH5 $\alpha$ [64] and E. coli MC1061 (Mobitec, Göttingen, Germany). Escherichia coli strains were grown in Luria-Bertani (LB), brain heart infusion (BHI) broth or solid agar $(1.5 \% \mathrm{w} / \mathrm{v})($ Biolab Diagnostics, Midrand, South Africa) and incubated at $37{ }^{\circ} \mathrm{C}$ with rotary shaking at $200 \mathrm{rpm}$. Forty micrograms per milliliter of 5-bromo-4-chloro-3-indolyl $\beta$-Dgalactopyranoside (X-gal) was added to $E$. coli LB growth media when required for blue-white colony screening. The probiotic LAB strains L. plantarum 423 and E. mundtii ST4SA were grown as static cultures at $30{ }^{\circ} \mathrm{C}$ in MRS broth (Biolab Diagnostics) or on MRS agar plates. Lactococcus lactis pNZ9000 was grown at $30{ }^{\circ} \mathrm{C}$ in $\mathrm{M} 17$ broth (Biolab Diagnostics) without shaking, or on agar plates supplemented with $0.5 \%(\mathrm{w} / \mathrm{v})$ glucose. Escherichia coli strains containing plasmids (Table 1) were cultured in LB or BHI medium supplemented with either $200 \mu \mathrm{g} /$ $\mathrm{ml} \mathrm{Em,} 10 \mu \mathrm{g} / \mathrm{ml} \mathrm{Cm}$ or $100 \mu \mathrm{g} / \mathrm{ml}$ ampicillin (Amp). Recombinant LAB strains containing plasmids, and integrative mutants (Table 2), were cultured in MRS or M17 medium supplemented with $10 \mu \mathrm{g} / \mathrm{ml} \mathrm{Em} \mathrm{or} 10 \mu \mathrm{g} / \mathrm{ml}$ Cm for L. plantarum 423, and $5 \mu \mathrm{g} / \mathrm{ml} \mathrm{Em}$ or $5 \mu \mathrm{g} / \mathrm{ml} \mathrm{Cm}$ for E. mundtii ST4SA and Lc. lactis pNZ9000. Listeria monocytogenes EGDe was grown in BHI media supplemented with $7.5 \mu \mathrm{g} / \mathrm{ml} \mathrm{Cm}$ and incubated at $37^{\circ} \mathrm{C}$ on an orbital shaker (200 rpm).

\section{DNA manipulation procedures and transformation}

Nucleic acid manipulations and general cloning procedures were carried out according to standard protocols, as described by Sambrook and Russel [65]. DNA 
restriction and modification enzymes were purchased from New England Biolabs (NEB, Ipswich, MA, USA) and were used as recommended by the manufacturer. Oligonucleotides were purchased from Inqaba Biotechnical Industries (Pretoria, South Africa). PCR amplifications were performed using Q5 high-fidelity PCR DNA polymerase (NEB) in a SwiftMinipro thermal cycler (Esco Healthcare, Malaysia). DNA fragments were purified from agarose gels using the Zymoclean ${ }^{\mathrm{TM}}$ gel DNA recovery kit (Zymo Research Corporation, Irvine, CA, USA). Escherichia coli plasmid DNA was purified using the PureYield $^{\mathrm{TM}}$ plasmid miniprep system (Promega, Madison, WI, USA). Genomic DNA (gDNA) of E. coli and LAB strains was purified using the ZR Fungal/Bacterial DNA miniprep kit (Zymo Research Corporation) following the manufacturer's instructions. Electrotransformation of E. coli, L. plantarum 423 and E. mundtii ST4SA was achieved as described previously [25], using the BioRad Gene Pulser electroporation system (Bio-Rad Laboratories, Hercules, CA, USA). Lactococcus lactis NZ9000 was electroporated as suggested by the supplier, using standard procedures (Mobitec).

\section{Construction of plasmids}

The integration vectors for use in L. plantarum 423 and $E$. mundtii ST4SA were based on the pNZ8048 Lc. lactis NICE system plasmid (Mobitec), containing the PnisA nisA gene promoter region, a multiple cloning site (MCS), E. coli/Lc. lactis repC and repA replication genes for replication in $\mathrm{LAB}$ and $E$. coli, the cat gene for $\mathrm{Cm}$ resistance and the termination $(\mathrm{T})$ sequence of the Lc. lactis pepN gene. DNA primers used are listed in Additional file 1: Table S2. The nisK and nisR regulatory genes were amplified from Lc. lactis pNZ9000 gDNA, using primers nisRK1 and nisRK2. The $2162 \mathrm{bp}$ amplicon was digested with HindIII and XhoI and cloned into pNZ8048 after digestion of the vector with the same restriction enzymes, yielding plasmid pNZnisRK. A schematic diagram summarizing the construction of pNZmazF and pNZmazFnisRK is shown in Additional file 1: Fig. S12. The pNZmazF and pNZmazFnisRK plasmids were constructed to test the functionality of the nisin-inducible promoter in Lc. lactis pNZ9000, $L$. plantarum 423 and E. mundtii ST4SA. The mazF toxin gene was amplified from genomic DNA isolated from $E$. coli $\mathrm{DH} 5 \alpha$, using primers mazF1 and mazF2. The generated $342 \mathrm{bp}$ amplicon was cloned into the MCSs of pNZ8048 and pNZnisRK, using NcoI and HindIII, to yield pNZmazF and pNZmazFnisRK, respectively. The integration vectors and their relevant characteristics are listed in Table 2.

The E. mundtii ST4SA munA bacteriocin gene knockout (KO) plasmid was constructed as follows. First, a complete $1809 \mathrm{bp}$ region of homology that included the munA ORF was obtained by PCR using the primer pair munAKO1/munAKO2, incorporating EcoRI and $X b a \mathrm{I}$ digestion sites (see Additional file 1: Fig. S2). The generated amplicon was digested with EcoRI/PvuII and HpaI/XbaI, resulting in a munA 911 bp upstream- and a 633 bp downstream-region of homology, respectively, and the removal of $18 \mathrm{bp}$ from the munA ORF. Next, the two regions of homology were joined together with a blunt-ended 2480 bp cat-ffluc gene cassette generated via PCR amplification using primer pair cat1/fluc2 and plasmid pGKVCatFflucST4SA (Additional file 1: Table S1) as source DNA. The cat-ffluc gene cassette contained the cat gene for chloramphenicol resistance and the firefly luciferase gene $(f f l u c)$ from Photinus pyralis fused to the strong constitutive E. mundtii ldh gene (Pstldh) promoter. This cat-ffluc-interrupted munA region was then cloned into the EcoRI/XbaI double-digested pBluescriptKS cloning vector, yielding plasmid pKSmunA::CatFfluc. Finally, the cat-ffluc gene cassette flanked by the munA upstream/downstream regions of homology (4024 bp) was PCR amplified from pKSmunA::CatFfluc and cloned into the StuI-linearized pNZmazFnisRKerm plasmid, containing both cat and erm antibiotic resistance genes, yielding plasmid pNZKOmunA::CatFfluc.

The L. plantarum 423 aap adhesion gene knockin (KI) plasmid was constructed by PCR, amplifying a $1848 \mathrm{bp}$ internal fragment of the aap ORF using primer pair aapKO1/aapKO2 (see Additional file 1: Fig. S13). The resulting amplicon was triple-digested with EcoRI/HpaI/XbaI (HpaI has a single cut site approximately in the middle of the aap fragment), and ligated to the blunt-ended flippase (FLP) recombination target (FRT)-flanked erm gene PCR fragment as well as the pBluescriptKS plasmid double-digested with EcoRI/XbaI, to yield plasmid pKSaap::FRTerm. The 1458 bp FRTflanked erm gene was generated using primer pair M13for/M13rev and plasmid pKSFRTerm as source DNA (see Additional file 1: Fig. S14). The FRT-erm gene flanked by the aap upstream/downstream regions of homology (3305 bp) was PCR amplified from pKSaap::FRTerm using primer pair aapKO1/aapKO2 and cloned into the blunt-ended (BglII, blunted) destination plasmid pNZmazFnisRK to yield plasmid pNZKIaap::FRTerm.

The E. mundtii ST4SA sortase A (srtA) deletion plasmid was constructed by amplifying two regions of homology flanking the $s r t A$ gene, using primer pairs, srtAKO1for/ srtAKO1rev and srtAKO2for/srtAKO2rev. The generated amplicons $(\sim 1 \mathrm{~kb}$ each) were designed to include small internal $(<60$-bp) fragments of the $s r t A$ ORF in both the upstream and downstream regions of homology (see Additional file 1: Fig. S9). The upstream and downstream regions were then digested with HindIII/HpaI 
Table 1 Bacterial strains and plasmids used in this study

\begin{tabular}{|c|c|c|}
\hline Strain or plasmid & Description & Reference or source \\
\hline \multicolumn{3}{|l|}{ Strains } \\
\hline \multicolumn{3}{|l|}{ E. coli } \\
\hline $\mathrm{DH} 5 \mathrm{a}$ & Host strain used for general subcloning & [61] \\
\hline MC1061 & $\begin{array}{l}\text { Host strain used for subcloning with Lc. lactis derived pNZ8048 vector; recA posi- } \\
\text { tive strain }\end{array}$ & Mobitec, Göttingen, Germany \\
\hline \multicolumn{3}{|l|}{ Lactobacillus plantarum } \\
\hline 423 & $\begin{array}{l}\text { Probiotic with multiple adhesion genes and a plantaricin bacteriocin producer; } \\
\text { forms part of the entiro }{ }^{\text {TM }} \text { probiotic; originally isolated from sorghum beer }\end{array}$ & Cipla Medpro (Pty.) Ltd. \\
\hline 423 pNZmazFnisRK & Contains the pNZmazFnisRK plasmid; $\mathrm{Cm}^{\mathrm{R}}$ & This study \\
\hline \multicolumn{3}{|l|}{ Enterococcus mundtii } \\
\hline ST4SA & $\begin{array}{l}\text { Probiotic with multiple adhesion genes and a mundticin bacteriocin producer; } \\
\text { forms part of the entiro }{ }^{\mathrm{TM}} \text { probiotic; originally isolated from soybeans }\end{array}$ & Cipla Medpro (Pty.) Ltd. \\
\hline ST4SA pNZmazFnisRK & Contains the pNZmazFnisRK plasmid; $\mathrm{Cm}^{\mathrm{R}}$ & This study \\
\hline \multicolumn{3}{|c|}{ Lactococcus lactis } \\
\hline pNZ9000 & $\begin{array}{l}\text { Standard host strain for nisin regulated gene expression; harbors the nis } R \text { and } \\
\text { nisK nisin regulatory genes integrated into the pep } N \text { gene locus }\end{array}$ & Mobitec, Göttingen, Germany \\
\hline pNZ9000 pNZmazF & Contains the pNZmazF plasmid; $\mathrm{Cm}^{\mathrm{R}}$ & This study \\
\hline \multicolumn{3}{|l|}{ Plasmids } \\
\hline pNZ8048 & $\begin{array}{l}\text { Broad-host range vector; } E \text {. coli shuttle vector; LAB expression vector containing } \\
\text { nisin A inducible-promoter (PnisA); } \mathrm{Cm}^{\mathrm{R}}\end{array}$ & Mobitec, Göttingen, Germany; [32] \\
\hline pGKV223D & E. colin $A B$ shuttle vector; $L A B$ expression vector with $L 23$ promoter; $E^{R}$ & University of Gröningen, The Netherlands \\
\hline pNZnisRK & $\begin{array}{l}\text { pNZ8048 vector carrying the nis } R \text { and nis } K \text { regulatory genes for cloning in } L A B \\
\text { strains that do not have the regulatory genes integrated onto the chromo- } \\
\text { some; } \mathrm{Cm}^{R}\end{array}$ & This study \\
\hline pNZmazF & $\begin{array}{l}\text { pNZ8048 vector carrying the E. coli mazF toxin gene under the control of the } \\
\text { PnisA promoter; } \mathrm{Cm}^{\mathrm{R}}\end{array}$ & This study \\
\hline pNZmazFnisRK & $\begin{array}{l}\text { pNZnisRK vector carrying the E. coli mazF toxin gene under the control of the } \\
\text { PnisA promoter; } \mathrm{Cm}^{\mathrm{R}}\end{array}$ & This study \\
\hline pNZmazFnisRKerm & $\begin{array}{l}\text { pNZ8048nisRK vector carrying the E. coli mazF toxin gene under the control of } \\
\text { the PnisA promoter and the erm gene; } \mathrm{Cm}^{\mathrm{R}}, \mathrm{Em}^{\mathrm{R}}\end{array}$ & This study \\
\hline pBluescriptKS & PCR cloning vector; $A m p^{R}$ & Stratagene, California, USA. \\
\hline PKSFRT & $\begin{array}{l}\text { pBluescriptKS plasmid carrying two flippase (FLP) recombination target } \\
\text { sequences (FRT) in a direct repeat orientation; } \text { Amp }^{R}\end{array}$ & This study \\
\hline pKSFRTErm & $\begin{array}{l}\text { pBluesriptKS plasmid carrying the erm gene flanked by two FRT sequences in a } \\
\text { direct repeat orientation; } \mathrm{Em}^{R}, \mathrm{Amp}^{R}\end{array}$ & This study \\
\hline pGKVPIdhFLP & $\begin{array}{l}\text { PGKV223D vector carrying the flippase (FLP) gene downstream of the constitu- } \\
\text { tive L. plantarum } 423 \text { lactate dehydrogenase gene Pldh promoter; Em }{ }^{R}\end{array}$ & This study \\
\hline pNZasRNA_repAnisRK & $\begin{array}{l}\text { pNZmazFnisRK vector carrying a } 350 \text { bp asRNA_repA transcript downstream of } \\
\text { the nisin-inducible PnisA promoter; } \mathrm{Cm}^{\mathrm{R}}\end{array}$ & This study \\
\hline pNZasFLPasRNA_repA & $\begin{array}{l}\text { pNZasRNA_repAnisRK vector carrying the flippase (FLP) gene downstream of the } \\
\text { constitutive L. plantarum } 423 \text { lactate dehydrogenase gene Pldh promoter; } \mathrm{Cm}^{R}\end{array}$ & This study \\
\hline
\end{tabular}

$\mathrm{Cm}^{R}$ : chloramphenicol resistance; $\mathrm{Em}^{\mathrm{R}}$ : erythromycin resistance; $\mathrm{Amp}^{\mathrm{R}}$ : ampicillin resistance

and $H p a \mathrm{I} / X b a \mathrm{I}$, respectively, ligated to the bluntended FRT-erm gene PCR fragment and pBluescriptKS digested with HindIII and XbaI, yielding plasmid pKSsrtA::FRTerm. The complete $s r t A$ region of homology including the FRT-erm gene was then PCR amplified from pKSsrtA::FRTerm using primer pair srtAKO1for/ srtAKO2rev, and cloned into the HindIII-linearized and blunt-ended plasmid pNZmazFnisRK, yielding plasmid
pNZKOsrtA::FRTerm. Construction of integration plasmids pNZKOplaA::ErmFfluc and pNZKOsrtC::FRTerm is described in the Additional file 1: Text $\mathrm{S} 1$ and shown in Additional file 1: Figs. S4 and S10.

Plasmids pKSFRTErm and pNZFLPasRNA_repA were constructed for utilization of the FLP/FRT recombination system of Saccharomyces cerevisiae for the generation of unmarked LAB KO mutants and antibiotic marker recycling, as follows (Additional file 1: Figs. S14 


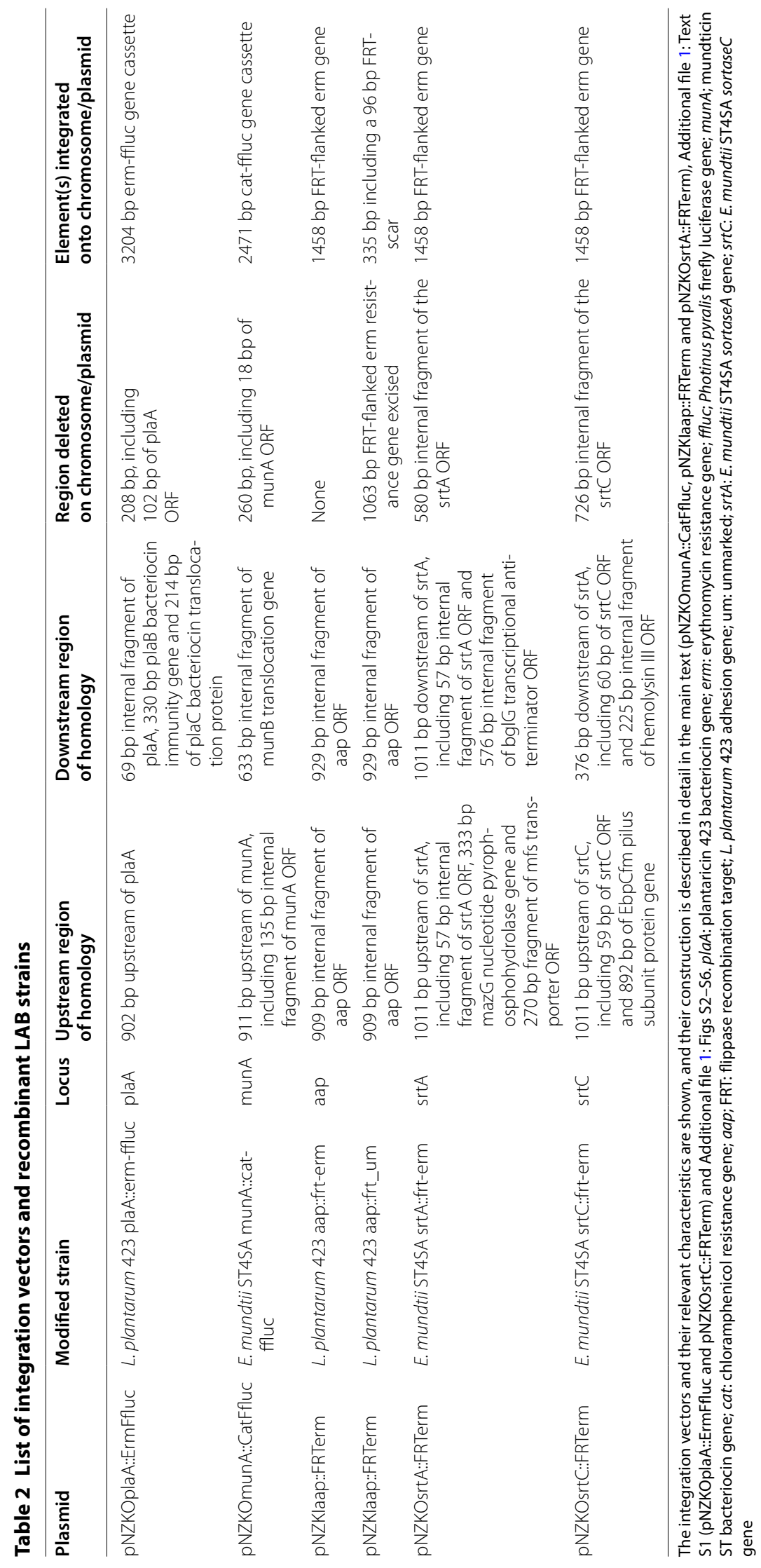


and S15). The pKSFRTErm plasmid was constructed by PCR amplification of two 48 bp FRT target sequences using primer pairs FRTfor1/FRTrev1, FRTfor2/FRTrev2 and the $S$. cerevisiae $2 \mu \mathrm{m}(\sim 6.4 \mathrm{~kb})$ plasmid as template DNA. The two generated amplicons containing the FRT target sequences were then double-digested with HindIII/SalI and BamHI/PstI, respectively, and cloned into the pBluescriptKS plasmid in a direct repeat orientation. The resulting plasmid (pKSFRT) was then digested with EcoRI (located in-between the two FRT repeats) and ligated to an erm gene PCR fragment (erm1/erm2 primer pair) digested with the same enzyme to yield plasmid pKSFRTErm (see Additional file 1: Fig. S14).

The pNZFLPasRNA_repA plasmid was constructed as follows. The 1284 bp flippase (FLP) gene was amplified from the $2 \mu \mathrm{m}$ plasmid using primer pair FLPfor/FLPrev, incorporating the NcoI/SalI digestion sites, and ligated to the EcoRI/NcoI double-digested Pldh promoter and double-digested EcoRI/SalI pGKV223D plasmid, yielding plasmid pGKVPldhFLP (see Additional file 1: Fig. S15). Next, a 350 bp repA antisense RNA (asRNA) PCR fragment was generated, using primers asRNAfor and asRNArev, and was fused upstream of the nisin-inducible promoter by digestion of the amplicon with $\mathrm{NcoI}$ and HindIII and cloned to the pNZmazFnisRK plasmid after digestion with the same restriction enzymes, creating pNZasRNA_repAnisRK. The asRNA_repA fragment was designed for inactivation of the RepA replication protein by binding to the first $350 \mathrm{bp}$ of the repA transcript as a reverse-and-complement RNA strand thus inhibiting its translation. Finally, the 1794 bp Pldh-FLP PCR fragment was amplified from plasmid pGKVPldhFLP using primer pair Pldh1/FLPrev and subsequently cloned into the BglII blunt-ended pNZasRNA_repAnisRK plasmid, yielding plasmid pNZFLPasRNA_repA (see Additional file 1: Fig. S15). The integrity of all plasmids constructed was verified by restriction digests and by PCR using appropriate primer combinations (Additional file 1: Table S2).

\section{Optimization of MazF toxin expression using the nisin-inducible promoter in LAB}

Control L. plantarum 423 and E. mundtii ST4SA strains transformed with empty pNZ8048 plasmid and recombinant L. plantarum 423 and E. mundtii ST4SA transformed with the pNZmazFnisRK plasmid were grown in MRS broth for $12 \mathrm{~h}$. One millilitre of the $12 \mathrm{~h}$ old cultures was used to inoculate $50 \mathrm{ml}$ of pre-warmed MRS broth. The $50 \mathrm{ml}$ cultures were supplemented with $0 \mathrm{ng} /$ $\mathrm{ml}, 100 \mathrm{ng} / \mathrm{ml}, 200 \mathrm{ng} / \mathrm{ml}, 300 \mathrm{ng} / \mathrm{ml}, 400 \mathrm{ng} / \mathrm{ml}$ and $600 \mathrm{ng} / \mathrm{ml}$ nisin (Sigma-Aldrich, St. Louis, MI, USA), respectively, and incubated at $30^{\circ} \mathrm{C}$ for $7 \mathrm{~h}$. Every $30 \mathrm{~min}$ the optical density $\left(\mathrm{OD}_{550 \mathrm{~nm}}\right)$ reading for each $50 \mathrm{ml}$ culture was measured. All experiments were done with three repeats. Expression of the mCherry reporter gene in Lc. lactis pNZ9000, L. plantarum 423 and E. mundtii ST4SA, placed under control of the PnisA nisin-inducible promoter was achieved as described in Additional file 1: Text S1. Agar plates streaked with fluorescing LAB cells were imaged using the IVIS.

\section{Confirmation of bacteriocin gene knockouts}

To confirm bacteriocin gene KO integration mutants of strains L. plantarum 423 and E. mundtii ST4SA an overlay lawn assay was performed as described by Van Zyl et al. [25] with the following modifications. The L. monocytogenes EGDe bacteriocin sensitive strain was grown for $12 \mathrm{~h}$ and $100 \mu \mathrm{l}$ plated onto a BHI agar plate. The cell-free supernatants (adjusted to $\mathrm{pH} 7.0$ with $\mathrm{NaOH}$ ) of actively growing $(12 \mathrm{~h})$ bacteriocin $\mathrm{KO}$ strains were collected by centrifugation $(8000 \times g$ for $5 \mathrm{~min})$. The supernatants were sterilized by passage through a $0.22-\mu \mathrm{m}$ pore size filter using a $5 \mathrm{ml}$ syringe and $30 \mu \mathrm{l}$ spotted into wells on BHI agar overlaid with L. monocytogenes EGDe. This was followed by incubation at $37^{\circ} \mathrm{C}$ for $24 \mathrm{~h}$. As positive controls, supernatant from WT strains was used. Additionally, bacteriocin $\mathrm{KO}$ strains were sonicated for 3 min using an Omni-Ruptor 400 (Omni International, Kennesaw, GA, USA) for release of intracellular proteins. Briefly, bacteriocin $\mathrm{KO}$ cultures were grown for $12 \mathrm{~h}$ in 100 MRS broth. Cells were harvested at $13,000 \times g$ for $10 \mathrm{~min}$, resuspended in $30 \mathrm{ml} 10 \mathrm{mM}$ Tris buffer supplemented with $500 \mathrm{mM} \mathrm{NaCl}$ and $10 \mathrm{mg} / \mathrm{ml}$ lyzozyme, and incubated at $37^{\circ} \mathrm{C}$ for $2 \mathrm{~h}$. After incubation, the cells were sonicated for $3 \mathrm{~min}$ followed by centrifugation $(13,000 \times g$ for $5 \mathrm{~min}$ ) and collection of the cell free supernatants. The supernatants containing intracellular proteins were then spotted onto BHI agar plates spread with L. monocytogenes EGDe as described before for visualization of inhibition zones. Expression of bioluminescence by $L$. plantarum 423 and E. mundtii ST4SA bacteriocin-negative strains was detected as described in Additional file 1: Text S1.

\section{Clumping response protocol}

The bacterial clumping protocol for confirmation of the E. mundtii ST4SA srtA gene KO strain was adapted from previous studies $[66,67]$ with the following modifications. A pheromone-containing supernatant was collected by centrifugation $(13,000 \times g$ for $5 \mathrm{~min})$ of a 12 -h old WT E. mundtii ST4SA strain, followed by filter sterilization through a $0.22-\mu \mathrm{m}$-pore size cellulose nitrate filter using a $5 \mathrm{ml}$ syringe. Wild-type and $s r t A \mathrm{KO}$ mutant strains were grown for $12 \mathrm{~h}$ in MRS broth and diluted to an $\mathrm{OD}_{600 \mathrm{~nm}}$ of $\sim 0.06$ in $5 \mathrm{ml}$ MRS broth supplemented with $250 \mu \mathrm{l}$ sterile supernatant from WT E. mundtii 
ST4SA. The cultures were incubated for $12 \mathrm{~h}$ at $30{ }^{\circ} \mathrm{C}$ without shaking before visualization of clumping.

\section{Confirmation of successful chromosomal or plasmid integrations}

To confirm successful double-crossover recombination events in $\mathrm{LAB}$ gene deletion or integration mutants, gDNA was isolated for PCR amplification using the appropriate primer combinations listed in Additional file 1: Table S2. All LAB KO or KI mutants were confirmed by DNA sequencing of PCR products performed by the Central DNA Sequencing Facility of Stellenbosch University.

\section{Protocol for isolating double-crossover mutants}

The complete step-by-step design and timeline for this method of quick and easy isolation of double-crossover KO or KI mutants is shown in Additional file 1: Fig. S6. Upon completion of the construction and transformation of an appropriate integration plasmid in LAB strains, transformants were enriched for by either direct inoculation into MRS broth or by plating onto MRS agar plates, supplemented with both $\mathrm{Cm}$ and Em. After an incubation period of $2-3$ days at $30{ }^{\circ} \mathrm{C}$, cells grown in broth or colonies observed on agar plates were streaked on fresh agar plates and re-incubated for $24 \mathrm{~h}$ at $30{ }^{\circ} \mathrm{C}$ until single colonies were observed. Cells carrying the integration plasmid were then inoculated into fresh MRS broth supplemented with $\mathrm{Cm}$ and $\mathrm{Em}$, followed by further incubation at $30{ }^{\circ} \mathrm{C}$ for $12 \mathrm{~h}$. Two-hundred microliters of the cell suspension was then inoculated into fresh MRS broth supplemented with the antibiotic present in the integrative gene cassette (either $\mathrm{Cm}$ or $\mathrm{Em}$ ) and the appropriate concentration of nisin for MazF toxin expression, followed by incubation at $30{ }^{\circ} \mathrm{C}$ for $6 \mathrm{~h}$. After $6 \mathrm{~h}$ of incubation and growth recorded at $\mathrm{OD}_{600 \mathrm{~nm}}$, the cell suspensions were serially diluted, and plated onto MRS agar plates supplemented with the appropriate antibiotic and nisin as described above. The plates were incubated for 24 to $48 \mathrm{~h}$ at $30{ }^{\circ} \mathrm{C}$ or until colonies were observed. Double-crossover recombined mutants appearing on the antibiotic-nisin plates were isolated and screened for the loss of the plasmid-backbone-located antibiotic marker and by PCR for confirmation of the desired recombination event.

Mutant LAB cells carrying an FRT-flanked erm gene were transformed with the pNZFLPasRNA_repA plasmid for excision of the erm resistance gene. Upon appearance of transformants on MRS agar plates supplemented with $\mathrm{Cm}$, single colonies were inoculated into MRS broth and incubated at $30{ }^{\circ} \mathrm{C}$ for $6 \mathrm{~h}$ for constitutive expression of FLP recombinase. Cell suspensions were then serially diluted and plated onto MRS agar plates containing $\mathrm{Cm}$ for propagation. Unmarked mutants that have lost the erm gene via FRT-FLP excision were identified by replica plating on MRS agar plates containing $\mathrm{Cm}$ or Em. Colonies that did not grow on MRS plates supplemented with Em were screened by PCR to confirm erm gene excision.

To generate unmarked mutants that would allow for further genetic manipulation using the nisin-MazF counter-selection marker system, cells carrying the FLP recombinase pNZFLPasRNA_repA plasmid were induced with nisin to stimulate loss of this plasmid. Cells carrying the pNZFLPasRNA_repA plasmid were inoculated into MRS broth supplemented with nisin, followed by incubation at $30^{\circ} \mathrm{C}$ for $6 \mathrm{~h}$ for expression of the asRNA transcript. After incubation, the cell suspensions were serially diluted, and plated onto MRS agar plates not supplemented with $\mathrm{Cm}$ and incubated at $30{ }^{\circ} \mathrm{C}$ for $24 \mathrm{~h}$. Mutant cells that have lost the pNZFLPasRNA repA plasmid were identified by replica plating on MRS agar plates supplemented with and without $\mathrm{Cm}$. Colonies that showed no growth on MRS plates supplemented with $\mathrm{Cm}$ indicated plasmid loss.

\section{Additional file}

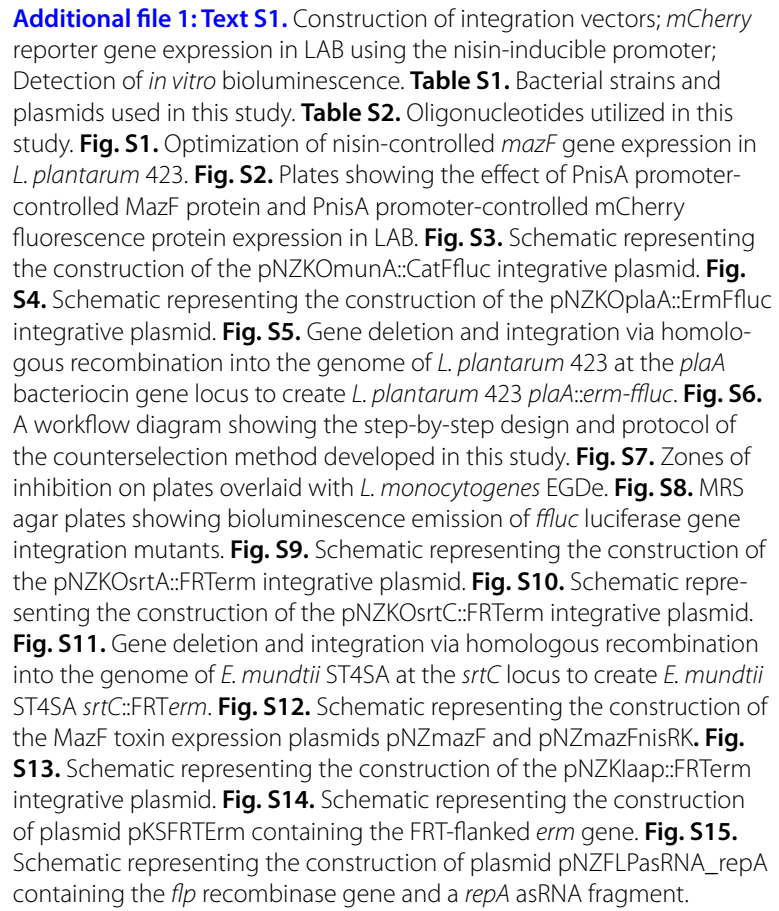

Additional file 1: Text S1. Construction of integration vectors; $m$ Cherry reporter gene expression in $L A B$ using the nisin-inducible promoter; Detection of in vitro bioluminescence. Table S1. Bacterial strains and plasmids used in this study. Table S2. Oligonucleotides utilized in this study. Fig. S1. Optimization of nisin-controlled mazF gene expression in L. plantarum 423. Fig. S2. Plates showing the effect of PnisA promotercontrolled MazF protein and PnisA promoter-controlled mCherry fluorescence protein expression in LAB. Fig. S3. Schematic representing the construction of the pNZKOmunA::CatFfluc integrative plasmid. Fig. S4. Schematic representing the construction of the pNZKOplaA::ErmFfluc integrative plasmid. Fig. S5. Gene deletion and integration via homologous recombination into the genome of L. plantarum 423 at the plaA bacteriocin gene locus to create L. plantarum 423 plaA::erm-ffluc. Fig. S6. A workflow diagram showing the step-by-step design and protocol of the counterselection method developed in this study. Fig. S7. Zones of inhibition on plates overlaid with L. monocytogenes EGDe. Fig. S8. MRS agar plates showing bioluminescence emission of ffluc luciferase gene integration mutants. Fig. S9. Schematic representing the construction of the pNZKOsrtA::FRTerm integrative plasmid. Fig. S10. Schematic representing the construction of the pNZKOsrtC::FRTerm integrative plasmid. Fig. S11. Gene deletion and integration via homologous recombination into the genome of E. mundtii ST4SA at the srtC locus to create E. mundtii ST4SA srtC::FRTerm. Fig. S12. Schematic representing the construction of the MazF toxin expression plasmids pNZmazF and pNZmazFnisRK. Fig. S13. Schematic representing the construction of the pNZKlaap::FRTerm integrative plasmid. Fig. S14. Schematic representing the construction of plasmid pKSFRTErm containing the FRT-flanked erm gene. Fig. S15. Schematic representing the construction of plasmid pNZFLPasRNA_repA containing the flp recombinase gene and a repA asRNA fragment.

\section{Abbreviations}

LAB: lactic acid bacteria; FLP: flippase; FRT: flippase recognition target; CRISPRs: clustered regularly interspaced palindromic repeats; Cas: CRISPR-associated; WT: wild-type; 5-FU: 5-fluorouracil; PnisA: nisin inducible promoter; NICE: nisincontrolled expression system; mRNA: messenger RNA; Em: erythromycin; Cm: 
chloramphenicol; Amp: ampicillin; IVIS: in vivo imaging system; um: unmarked; asRNA: antisense RNA; gDNA: genomic DNA; KO: knockout; Kl: knockin; AS: aggregation substance; ORF: open reading frame; ori: origin of replication; X-gal: 5-bromo-4-chloro-3-indolyl $\beta$-D-galactopyranoside.

\section{Authors' contributions}

WVZ conducted the research. LMTD and SMD assisted with the designing of the experiments and evaluated the data. All authors contributed equally in the writing of the paper. All authors read and approved the final manuscript.

\section{Acknowledgements}

We thank Dr. Anton Van Staden for his technical support and valuable discussions of the data.

\section{Competing interests}

The authors declare that they have no competing interests.

\section{Availability of data and materials}

The datasets and vectors generated and/or analysed during the current study are included in the published article and are also available from the corresponding author on reasonable request.

\section{Consent to publish}

Not applicable.

\section{Ethics approval and consent to participate}

Not applicable.

\section{Funding}

This work was supported by the National Research Foundation of South Africa (Grant No. 103843).

\section{Publisher's Note}

Springer Nature remains neutral with regard to jurisdictional claims in published maps and institutional affiliations.

Received: 19 November 2018 Accepted: 21 March 2019 Published online: 29 March 2019

\section{References}

1. Varankovich NV, Nickerson MT, Korber DR. Probiotic based strategies for therapeutic and prophylactic use against multiple gastrointestinal diseases. Front Microbiol. 2015;6:685

2. Macpherson AJ, Harris NL. Interactions between commensal intestinal bacteria and the immune system. Nat Rev Immunol. 2004;4:478-85.

3. Frick JS, Schenk K, Quitadamo M, Kahl F, Köberle M, Bohn E, Aepfelbacher $\mathrm{M}$, Autenrieth IB. Lactobacillus fermentum attenuates the proinflammatory effect of Yersinia enterocolitica on human epithelial cells. Inflamm Bowel Dis. 2007;13:83-90.

4. Gourbeyre P, Denery S, Bodinier M. Probiotics, prebiotics, and synbiotics: impact on the gut immune system and allergic reactions. J Leukoc Biol. 2011;89:685-95.

5. Liong M. Probiotics: biology, genetics and health aspects. Microbiology monographs. Berlin: Springer; 2011.

6. Marco ML, Pavan S, Kleerebezem M. Towards understanding molecular modes of probiotic action. Curr Opin Biotechnol. 2006;17:204-10.

7. Collins JJ, Endy D, Hutchison CA, Roberts RJ. Editorial-synthetic biology. Nucleic Acids Res. 2010;38:2513.

8. Ike Y, Craig RA, White BA, Yagi Y, Clewell DB. Modification of Streptococcus faecalis sex pheromones after acquisition of plasmid DNA. Proc Natl Acad Sci USA. 1983:80:5369-73

9. Josson K, ScheirlinckT, Michiels F, Platteeuw C, Stanssens P, Joos H, Dhaese P, Zabeau M, Mahillion J. Characterization of a gram-positive broad-host-range plasmid isolated from Lactobacillus hilgardii. Plasmid. 1989;21:9-20

10. Posno M, Leer RJ, van Luijk N, van Giezen MJF, Heuvelmans PTHM, Lokman BC, Pouwels PH. Incompatibility of Lactobacillus vectors with replicons derived from small cryptic Lactobacillus plasmids and segregational instability of the introduced vectors. Appl Environ Microbiol. 1991;57:1822-8.

11. Fang F, O'Toole PW. Genetic tools for investigating the biology of commensal lactobacilli. Front Biosci. 2009;14:3111-27.

12. Van ZyI WF, Deane SM, Dicks LMT. Reporter systems for in vivo tracking of lactic acid bacteria. Gut Microbes. 2015;6:291-9.

13. Itaya M, Tanaka T. Gene-directed mutagenesis on the chromosome of Bacillus subtilis. Mol Gen Genet. 1990:223:268-72.

14. Oh J, van Pijkeren J. CRISPR-Cas9-assisted recombineering in Lactobacillus reuteri. Nucleic Acids Res. 2014;17:e131.

15. van Pijkeren J, Neoh KM, Sirias D, Findley AS, Britton RA. Exploring optimization parameters to increase ssDNA recombineering in Lactococcus lactis and Lactobacillus reuteri. Bioengineered. 2012;3:209-17.

16. van Pijkeren JP, Britton RA. High efficiency recombineering in lactic acid bacteria. Nucleic Acids Res. 2012;40:e76.

17. Itaya M, Fujita K, Kuroki A, Tsuge K. Bottom-up genome assembly using the Bacillus subtilis genome vector. Nat Methods. 2008:5:41-3.

18. Chopin MC, Chopin A, Rouault A, Galleron N. Insertion and amplification of foreign genes in the Lactococcus lactis subsp. lactis chromosome. Appl Environ Microbiol. 1989;55:1769-74.

19. Casey J, Daly C, Fitzgerald GF. Chromosomal integration of plasmid DNA by homologous recombination in Enterococcus faecalis and Lactococcus lactis subsp. lactis hosts harbouring Tn919. Appl Environ Microbiol. 1991;57:2677-82.

20. Duncan $\mathrm{CH}$, Wilson GA, Young FE. Mechanism of integrating foreign DNA during transformation of Bacillus subtilis. Proc Natl Acad Sci USA. 1978;75:3664-8.

21. Raibauld O, Mock M, Schwartz M. A technique for integrating any DNA fragment into the chromosome of Escherichia coli. Gene. 1984;29:231-41.

22. Pozzi G, Guild WR. Modes of integration of heterologous plasmid DNA into the chromosome of Streptococcus pneumoniae. J Bacteriol. 1985;161:909-12.

23. Leenhouts K, Kok JJ, Venema G. Campbell-like integration of heterologous plasmid DNA into the chromosome of Lactococcus lactis subsp. lactis. Appl Environ Microbiol. 1989;55:394-400.

24. Scheirlinck T, Mahillon J, Joos H, Dhaese P, Michiels F. Integration and expression of a-amylase and endoglucanase genes in the Lactobacillus plantarum chromosome. Appl Environ Microbiol. 1989;55:2130-7.

25. Van ZyI WF, Deane SM, Dicks LMT. Use of the mCherry fluorescent protein to study intestinal colonization by Enterococcus mundtii ST4SA and Lactobacillus plantarum 423 in mice. Appl Environ Microbiol. 2015;81:5993-6002.

26. Reyrat JM, Pelicic V, Gicquel B, Rappuoli R. Counterselectable markers: untapped tools for bacterial genetics and pathogenesis. Infect Immun. 1998:66:4011-7.

27. Heap JT, Ehsaan M, Cooksley CM, Ng Y, Cartman ST, Winzer K, Minton MP. Integration of DNA into bacterial chromosomes from plasmids without a counter selection marker. Nucleic Acids Res. 2012;40:e59.

28. Martinussen J, Hammer K. Cloning and characterization of upp, a gene encoding uracil phosphoribosyltransferase from Lactococcus lactis. J Bacteriol. 1994;176:6457-63.

29. Martinussen J, Hammer K. Powerful methods to establish chromosomal markers in Lactococcus lactis: an analysis of pyrimidine salvage pathway mutants obtained by positive selections. Microbiology. 1995;141:1883-90.

30. Stibitz S. Use of conditionally counterselectable suicide vectors for allelic exchange. Methods Enzymol. 1994;235:458-65.

31. Stacey KA, Simson E. Improved method for the isolation of thyminerequiring mutants of Escherichia coli. J Bacteriol. 1965;173:1502-8.

32. Maloy SR, Nunn WD. Selection for loss of tetracycline resistance by Escherichia coli. J Bacteriol. 1981;145:1110-2.

33. Bernard P, Gabant P, Bahassi EM, Couturier M. Positive selection vectors using the F plasmid $c c d B$ killer gene. Gene. 1994;148:71-4.

34. Sander P, Meier A, Böttger EC. rpsL1: a dominant selectable marker for gene replacement in mycobacteria. Mol Microbiol. 1995;16:991-1000.

35. Zhang X, Yan X, Cui Z, Hong Q, Li S. mazF, a novel counter-selectable marker for unmarked chromosomal manipulation in Bacillus subtilis. Nucleic Acids Res. 2006;34:e71.

36. Al-Hinai MA, Fast AG, Papoutsakis ET. Novel system for efficient isolation of Clostridium double-crossover allelic exchange mutants enabling 
markerless chromosomal gene deletions and DNA integrations. Appl Environ Microbiol. 2012;78:8112-21.

37. Mierau I, Kleerebezem M. 10 years of the nisin-controlled gene expression system (NICE) in Lactococcus lactis. Appl Microbiol Biotechnol. 2006;68:705-17.

38. Kleerebezem M, Beerthyuzen MM, Vaughan EE, de Vos WM, Kuipers OP. Controlled gene expression systems for lactic acid bacteria: transferable nisin-inducible expression cassettes for Lactococcus, Leuconostoc, and Lactobacillus. Appl Environ Microbiol. 1997;63:4581-4.

39. Ribardo DA, Mclver KS. amrA encodes a putative membrane protein necessary for maximal exponential phase expression of the Mga virulence regulon in Streptococcus pyogenes. Mol Microbiol. 2003;50:673-85.

40. Kuipers OP, de Ruyter PGGA, Kleerebezem M, de Vos WM. Quorum sensing-controlled gene expression in lactic acid bacteria. J Biotechnol. 1998;64:15-21.

41. Gerdes K, Christensen SK, Lobner-Olesen A. Prokaryotic toxin-antitoxin stress response loci. Nat Rev Microbiol. 2005;3:371-82.

42. Zhang Y, Zhang J, Hara H, Kato I, Inouye M. Insights into the mRNA cleavage mechanism by MazF, an mRNA interferase. J Biol Chem. 2005;280:3143-50.

43. Knoetze H. Characterization of a broad-spectrum antimicrobial peptide from Enterococcus mundtii active against bacteria associated with middle ear infections. MSc. thesis. Department of Microbiology, Stellenbosch University, Stellenbosch, South Africa. 2006.

44. Van Reenen CA, Van Zyl WH, Dicks LMT. Expression of the immunity protein of plantaricin 423 , produced by Lactobacillus plantarum 423 , and analysis of the plasmid encoding the bacteriocin. Appl Environ Microbiol. 2006;72:7644-51.

45. Solem C, Defoor E, Ruhdal P, Martinussen J. Plasmid pCS1966, a new selection/counterselection tool for lactic acid bacterium strain construction based on the oroP gene, encoding an orotate transporter from Lactococcus lactis. Appl Environ Microbiol. 2008;74:4472-775.

46. Hensel M, Holden DW. Molecular genetic approaches for the study of virulence in both pathogenic bacteria and fungi. Microbiology. 1996;142:1049-58.

47. de Ruyter PG, Kuipers OP, Beerthuyzen MM, Alen-Boerrigter I, de Vos WM. Functional analysis of promoters in the nisin gene cluster of Lactococcus lactis. J Bacteriol. 1996;178:3434-9.

48. de Ruyter PG, Kuipers OP, de Vos WM. Controlled gene expression systems for Lactococcus lactis with the food-grade inducer nisin. Appl Environ Microbiol. 1996;62:3662-7.

49. Van Reenen CA, Dicks LMT, Chikindas ML. Isolation, purification and partial characterization of plantaricin 423 , a bacteriocin produced by Lactobacillus plantarum. J Appl Microbiol. 1998:84:1131-7.

50. Vetter D, Andrews BJ, Roberst-Beatty L, Sadowski PD. Site-specific recombination of yeast 2- $\mu \mathrm{m}$ DNA in vitro. Proc Natl Acad Sci USA. 1983:80:7284-8.

51. Kopke K, Hoff B, Kück U. Application of the S. cerevisiae FLP/FRT recombination system in filamentous fungi for marker recycling and construction of knockout strains devoid of heterologous genes. Appl Environ Microbiol. 2010;76:4664-74.
52. Schweizer HP. Applications of the Saccharomyces cerevisiae FLP-FRT system in bacterial genetics. J Mol Microbiol Biotechnol. 2003;5:67-77.

53. Chang CJ, Chen PT, Chao YP. Replicon-free and markerless methods for genomic insertion of DNAs in phage attachment sites and controlled expression of chromosomal genes in Escherichia coli. Biotechnol Bioeng. 2008;101:985-95.

54. Sharan SK, Thomason C, Kuznetsov SG, Court DL. Recombineering: a homologous recombination-based method of genetic engineering. Nat Protoc. 2009:4:206-23.

55. Ramiah K, Van Reenen CA, Dicks LMT. Expression of the mucus adhesion genes Mub and MapA, adhesion-like factor EF-Tu and bacteriocin gene plaA of Lactobacillus plantarum 423, monitored with real-time PCR. Int J Food Microbiol. 2007;116:405-9.

56. Good L. Translation repression by antisense sequences. Cell Mol Life Sci. 2003;60:854-61.

57. Walker SH, Klaenhammer T. An explosive antisense RNA strategy for inhibition of a lactococcal bacteriophage. Appl Environ Microbiol. 2000:66:310-9.

58. Sturino JM, Klaenhammer T. Expression of antisense RNA targeted against Streptococcus thermophilus bacteriophages. Appl Environ Microbiol. 2002;68:588-96.

59. Tummala SB, Welker NE, Papoutsakis ET. Design of antisense RNA constructs for downregulation of the acetone formation pathway of Clostridium acetobutylicum. J Bacteriol. 2003;185:1923-34.

60. Bouazzaoui K, LaPointe G. Use of antisense RNA to modulate glycosyltransferase gene expression and exopolysaccharide molecular mass in Lactobacillus rhamnosus. J Microbiol Methods. 2006;65:216-25.

61. Raju D, Setlow P, Sarker MR. Antisense-RNA-mediated decreased synthesis of small, acid-soluble spore proteins leads to decreased resistance of Clostridium perfringens spores to moist heat and UV radiation. Appl Environ Microbiol. 2007:73:2048-53.

62. Oddone GM, Mills DA, Block DE. Dual inducible expression of recombinant GFP and targeted antisense RNA in Lactococcus lactis. Plasmid. 2009;62:108-18.

63. Darsonval $\mathrm{M}, \mathrm{Msadek} T$, Alexandre $\mathrm{H}$, Grandvalet $\mathrm{C}$. The antisense RNA approach: a new application for in vivo investigation of the stress response of Oenococcus oeni, a wine-associated lactic acid bacterium. Appl Environ Microbiol. 2015;82:18-26.

64. Ausubel FM, Brent R, Kingston RE, Moore DD, Seidman JG, Smith JA, Struhl K. Current protocols in molecular biology. New York: Wiley; 1994.

65. Sambrook J, Russell D. Molecular cloning: a laboratory manual. 3rd ed. Cold Spring Harbor: Cold Spring Harbor Laboratory Press; 2001.

66. Donelli D, Paoletti C, Baldassari L, Guaglianone E, Di Rosa R, Magi G, Spinaci C, Facinelli B. Sex pheromone response, clumping, and slime production in enterococcal strains isolated from occluded biliary stents. J Clin Microbiol. 2004:42:3418-27.

67. Kline KA, Kau AL, Chen SW, Lim A, Pinker JS, Rosch J, Nallapareddy SR, Murray BE, Henriques-Normark B, Beatty W, Caparon MG, Hultgren SJ. Mechanism for sortase localization and the role of sortase localization in efficient pilus assembly in Enterococcus faecalis. J Bacteriol. 2009;191:3237-47.

Ready to submit your research? Choose BMC and benefit from

- fast, convenient online submission

- thorough peer review by experienced researchers in your field

- rapid publication on acceptance

- support for research data, including large and complex data types

- gold Open Access which fosters wider collaboration and increased citations

- maximum visibility for your research: over 100M website views per year

At BMC, research is always in progress.

Learn more biomedcentral.com/submissions 